\title{
EFEKTIFITAS PEMBENTUKAN KAMPUNG KB SEBAGAI INDIKATOR PERUBAHAN PERILAKU MASYARAKAT DI JL. MUHARTO GANG 5B RW 08 KELURAHAN KOTALAMA MALANG
}

\author{
Effectiveness of the Establishment of the KB Village as an Indicator of Community Behavior \\ Change on Jl. Muharto Gang 5B Rw 08 Kelurahan Kotalama Malang
}

\author{
Nining Loura Sari ${ }^{1}$, Eka Supriyanti ${ }^{2}$
}

1. Sekolah Tinggi Ilmu Kesehatan Maharani, Malang

\section{Riwayat artikel \\ Diajukan: Juli 2020 \\ Diterima: September 2020

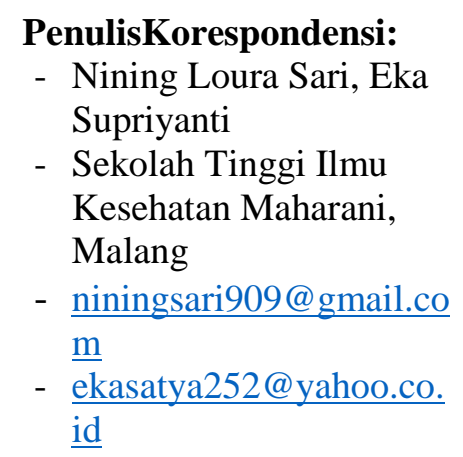

Kata Kunci:

Pembentukan Kampung KB,

Perilaku Masyarakat

\begin{abstract}
Abstrak
Kampung KB merupakan salah satu upaya penguatan Program KKBPK yang dikelola dan diselenggarakan dari, oleh dan untuk masyarakat dalam memberdayakan dan memberikan kemudahan kepada masyarakat. Penelitian ini bertujuan untuk melihat perilaku masyarakat dengan adanya kampung KB. Metode penelitian kuantitatif dengan metode cross sectional. Alat pengumpulan data berupa kuesioner dengan sampel sebanyak 100 responden. Penelitian ini menggunakan teknik purposive sampling. Uji statistik menggunakan chi-square dan fisher exact pada analisis univariat dan bivariat. Hasil penelitian didapatkan efektifitas pembentukan kampung KB responden sedang $(50 \%)$, perilaku responden $(62 \%)$ cukup dan hasil uji korelasi Spearman diperoleh nilai sig.(2-tailed) sebesar 0,00 sehingga $\rho<0,01(\alpha)$ diketahui bahwa ada hubungan efektifitas pembentukan kampung $\mathrm{KB}$ dengan perubahan perilaku masyarakat. Kampung KB di Jl. Muharto Gang 5B Rw 08 Kelurahan Kotalama Malang membutuhkan apresiasi serta dukungan yang besar dari berbagai pihak atas semua kegiatan yang telah dikelola, sehingga delapan indikator proses kampung KB yang dimulai sejak tahun 2017 dan berakhir pada tahun 2019 dapat tercapai dengan perubahan perilaku masyarakat yang lebih baik lagi.
\end{abstract}

\begin{abstract}
$\mathrm{KB}$ Village is one of the KKBPK strengthening programs that is managed and managed from, by and for the community to empower and provide facilities for the community. This study aims to look at the relationship between the community and the existence of KB villages. Quantitative research methods with cross sectional methods. The data collection tool consisted of a questionnaire with a sample of 100 respondents. This research uses purposive sampling technique. Statistical tests using chi-square and fisher precisely in the univariate and bivariate analysis. The results of the study found that the effectiveness of the KB respondents' village formation was moderate $(50 \%)$, the respondent's behavior $(62 \%)$ was sufficient and the Spearman trial results obtained sig. (2-tailed) of 0.00 so $\rho<0.01(\alpha)$ there is a relationship between the effectiveness of the formation of the $\mathrm{KB}$ village with changes in society. KB Village on J1. Muharto Gang 5B Rw 08 Kotalama Malang needs great appreciation and support from various needs that have been managed, so that it becomes an indicator of the $\mathrm{KB}$ village process that began in 2017 and ends in 2019 that can be adjusted to the needs of the community better.
\end{abstract}

\section{Pendahuluan}

Kelurahan Kotalama merupakan bagian dari Kecamatan Kedungkandang yang memiliki luas hanya $1 \mathrm{~km} 2$ dan hanya berjarak kurang lebih $1 \mathrm{~km}$ dari Balaikota Malang. Batas administratif sebelah utara Kelurahan Jodipan (Kec. Blimbing), sebelah selatan Kelurahan Mergosono (Kec. Kedungkandang), sebelah barat Kelurahan Sukoharjo (Kec. Klojen) dan sebelah timur
Kelurahan Kedung kandang (http://kampungkb.bkkbn.go.id/kampungkb/ profile/3350).Lokasi penggarapan Kampung KB di RW 08 sejak tahun 2017.

Pada awal tahun 2016 Badan Kependudukan dan Keluarga Berencana Nasional (BKKBN) sebagai Lembaga Non Kementerian yang bertanggung jawab terhadap pelaksanaan program Kependudukan Keluarga Berencana dan 
Pembangunan Kampung KB sebagai upaya pembangunan keluarga sejahtera yang terakumulasi dalam 4 pokok garapan yaitu pendewasaan usia perkawinan, pengaturan kelahiran, pemantapan ketahanan keluarga dan pemberdayaan ekonomi keluarga serta ditambah dengan pengendalian, pemantauan, pengamatan serta pembinaan penduduk merupakan bagian dari pengentasan kemiskinan (BKKBN, 2017). Mulai dari aspek ekonomi, pendidikan, perkembangan teknologi, peningkatan akses kesehatan, peningkatan dalam infrastruktur yang tersedia dan peningkatan dalam pendapatan serta kemakmuran masyarakat (Raikhani, A., Yunas Setia, N., Ratnasari, L., \& Hariastuti, I.2016). Salah satu bentuk revitalisasi program KKBPK (Kependudukan dan KB Pembangunan.

Keluarga) adalah kampung KB yang berada di Jl. Muharto Gang 5B RW 08 Kelurahan Kotalama Kecamatan Kedungkandang Malang dimana di RW 08 termasuk dalam wilayah pinggiran, di dominasi etnis Madura, padat penduduknya, tingkat pendidikannya masih rendah, tingkat ekonomi masyarakat menengah ke bawah dengan mata pencaharian didominasi sektor pekerja lepas seperti pemulung, tukang becak, kuli batu dan berdagang dipasar/wiraswasta, serta masih banyaknya pernikahan dini.

Keluarga (KKBPK) secara nasional membuat terobosan baru yang bersifat kedaerahan dan bernuansa kearifan lokal yang disebut istilah "Kampung KB" atau lengkapnya"Kampung Keluarga Berencana" (Elisa Setiawati, 2017).

Melihat perubahan perilaku masyarakat dengan adanya kampung KB di RW 08, merupakan tujuan utama. Hal ini berkaitan dengan program kampung $\mathrm{KB}$ yang didasarkan pada indikator input, proses dan output. Utamnya kita melihat dari indikator proses pelaksanaan kampung $\mathrm{KB}$ meliputi peningkatan frekuensi dan kualitas advokasi dan KIE, peningkatan kualitas pelayanan $\mathrm{KB}$ dan $\mathrm{KR}$, pertemuan berkala kelompok kegiatan BKB, BKR, BKL, UPPKS, pertemuan IMP, staf meeting dan lokakarya mini serta pelayanan taman posyandu (PAUD, Kesehatan/Posyandu dan BKB), surat nikah, akta kelahiran, KTP. Untuk kegiaatannya meliputi kegiatan seksi keagamaan, kegiatan seksi pendidikan, kegiatan seksi reproduksi, kegiatan seksi ekonomi, kegiatan seksi perlindungan, kegiatan seksi kasih sayang, kegiatan seksi sosial budaya dan kegiatan seksi pembinaan lingkungan (BKKBN, 2017).

Kampung KB merupakan upaya membumikan program $\mathrm{KB}$ serta dijadikan upaya revitalisasi program KKBPK (Kependudukan dan KB Pembangunan Keluarga). Badan kependudukan dan Keluarga Berencana Nasional (BKKBN) diberi mandat untuk dapat turut mensukseskan Agenda Prioritas Pembangunan (Nawacita), terutama pada Agenda Prioritas nomor 5 (lima) "Meningkatkan Kualitas Hidup manusia Indonesia" melalui Pembangunan Kependudukan dan Keluarga berencana, serta melaksanakan Strategi Pembangunan Nasional 2015-2019 (Dimensi Pembangunan) untuk dimensi pembangunan manusia pada pembangunan bidang kesehatan dan mental/karakter (Revolusi Mnetal). Dalam hal ini kemudian disepakati agar BKKBN segera dapat membentuk Kampung Keluarga Berencana (Kampung KB) (BKKBN, 2015).

Kampung KB merupakan salah satu bentuk/model miniatur pelaksanaan total Program KKBPK secara utuh yang melibatkan seluruh bidang dilingkungan BKKBN dan bersinergi dengan Kementerian/Lembaga, mitra kerja, stakeholders instansi terkait sesuai dengan kebutuhan dan kondisi wilayah serta dilaksanakan ditingkat pemerintahan terendah (sesuai prasyarat penentuan lokasi kampung KB) diseluruh Kabupaten dan Kota (BKKBN, 2015). Kampung KB ini mencoba memadukan konsep pembangunan terpadu bidang Kependudukan. Keluarga Berencana dan Pembangunan Keluarga (KKB-PK).

Partisipasi langsung masyarakat setempat serta berbagai instansi dalam 
Kampung KB sangat penting sehingga pelayanan paripurna dapat dirasakan langsung oleh masyarakat menuju kesejahteraan rakyat. Hal ini mendorong peneliti untuk melakukan penelitian tentang efektifitas pembentukan kampung $\mathrm{kb}$ sebagai indikator perubahan perilaku masyarakat di Jl. Muharto Gang 5b RW 08 Kelurahan Kotalama Malang.

\section{Metodologi}

Penelitian ini merupakan penelitian kuantitatif dengan metode cross sectional yaitu suatu penelitian non eksperimental. Metode pengambilan data menggunakan kuesioner. Penelitian ini dilaksanakan di Jl. Muharto Gang 5B RW 08 Kelurahan Kotalama, Kecamatan Kedung Kandang Kota Malang dan pengambilan sampel dilakukan dengan teknik purposive sampling. Sampel adalah seluruh warga yang berada di wilayah Jl. Muharto Gang 5B RW 08 Kelurahan Kotalama, Kecamatan Kedungkandang Kota Malang dengan jumlah 100 responden yang memenuhi kriteria inklusi. Kriteria inklusi responden sebagai berikut: Masyarakat yang tinggal di wilayah Jl. Muharto Gang 5B RW 08 Kelurahan Kotalama, Kecamatan Kedungkandang Malang, laki-laki dan perempuan yang bisa memahami bahasa Indonesia (Membaca dan menulis). Sedangkan criteria eksklusi: laki-laki dan perempuan yang tidak mengalami gangguan jiwa.

Penelitian dilakukan mulai bulan April s/d Juli 2019 di Jl. Muharto Gang 5B RW 08 Kelurahan Kotalama, Kecamatan Kedungkandang Malang. Pengambilan data menggunakan kuesioner. Data dianalisis dengan uji korelasi Spearman Rank.

\section{Hasil dan Pembahasan \\ HASIL \\ Data Umum}

Tabel 1 Distribusi frekuensi karakteristik responden menurut golongan umur di $\mathrm{Jl}$. Muharto Gang 5B Rw 08 Kelurahan Kotalama, Kecamatan Kedung Kandang Kota Malang.

\begin{tabular}{ccc}
\hline No & $\begin{array}{c}\text { Golongan } \\
\text { Umur }\end{array}$ & $\mathrm{F}$ \\
\hline 1. & $17-19$ th & 11 \\
2. & $20-40$ th & 58 \\
3. & $41-65$ th & 23 \\
4. & $66-75$ th & 8 \\
\hline & Total & 100 \\
\hline
\end{tabular}

Sumber: Data primer hasil penelitian, 2019

Tabel 2 Distribusi frekuensi karakteristik responden menurut jenis kelamin di Jl. Muharto Gang 5B Rw 08 Kelurahan Kotalama, Kecamatan Kedung Kandang Kota Malang.

\begin{tabular}{lll}
\hline No & $\begin{array}{c}\text { Jenis } \\
\text { Kelamin }\end{array}$ & $\mathrm{F}$ \\
\hline 1. & Laki-laki & 22 \\
2. & Perempuan & 78 \\
\hline & Total & 100 \\
\hline
\end{tabular}

Sumber: Data primer hasil penelitian, 2019

Tabel 3 Distribusi frekuensi karakteristik responden menurut jenis pendidikan terakhir di Jl. Muharto Gang 5B Rw 08 Kelurahan Kotalama, Kecamatan Kedung Kandang Kota Malang.

\begin{tabular}{ccc}
\hline No & Pendidikan & F \\
\hline 1. & $\begin{array}{c}\text { Tidak } \\
\text { tamat SD }\end{array}$ & 9 \\
2. & SD & 32 \\
3. & SLTP & 13 \\
4. & SLTA & 22 \\
5. & Diploma & 12 \\
6. & Sarjana & 12 \\
\hline & Total & 100
\end{tabular}

Sumber: Data primer hasil penelitian,2019

Tabel 4 Distribusi frekuensi karakteristik responden menurut jenis pekerjaan di Jl. Muharto Gang 5B Rw 08 Kelurahan Kotalama, Kecamatan Kedung Kandang Kota Malang.

\begin{tabular}{ccc}
\hline No & Pendidikan & F \\
\hline 1. & $\begin{array}{c}\text { IRT/Tidak } \\
\text { bekerja }\end{array}$ & 9 \\
\hline
\end{tabular}




\begin{tabular}{ccc}
\hline 2. & Petani/Buruh & 32 \\
3. & PNS & 13 \\
4. & Swasta & 22 \\
5. & Wiraswasta & 12 \\
6. & Mahasiswa & 12 \\
\hline & Total & 100 \\
\hline
\end{tabular}

Sumber: Data primer hasil penelitian, 2019

\section{Data khusus}

Tabel 5 Distribusi frekuensi efektifitas pembentukan kampung KB di Jl. Muharto Gang 5B Rw 08 Kelurahan Kotalama, Kecamatan Kedung Kandang Kota Malang.

\begin{tabular}{ccc}
\hline No & Kriteria & $\mathrm{F}$ \\
\hline 1. & Rendah & 4 \\
2. & Sedang & 50 \\
3. & Tinggi & 46 \\
\hline & Total & 100
\end{tabular}

Sumber: Data primer hasil penelitian, 2019 Tabel 6 Distribusi frekuensi perilaku masyarakat di J1. Muharto Gang 5B Rw 08 Kelurahan Kotalama, Kecamatan Kedung Kandang Kota Malang.

\begin{tabular}{lcc}
\hline No & Kriteria & F \\
\hline 1. & Kurang & 2 \\
2. & Cukup & 62 \\
3. & Baik & 36 \\
\hline & Total & 100
\end{tabular}

Sumber: Data primer hasil penelitian, 2019

Tabel 7 Analisa hubungan Efektivitas Pembentukan Kampung KB sebagai Indikator Perubahan Perilaku Masyarakat di Jl. Muharto Gang 5B RW 08 Kelurahan Kotalama, Kecamatan Kedung Kandang Kota Mala Perilaku Masyarakat Total

\begin{tabular}{|c|c|c|c|c|c|c|}
\hline \multicolumn{2}{c|}{} & Kurang & Cukup & Baik & \\
\hline \multirow{4}{*}{$\begin{array}{c}\text { Pemben } \\
\text { tukan }\end{array}$} & $\begin{array}{c}\text { Rend } \\
\text { ah }\end{array}$ & $\sum$ & 2 & 2 & 0 & 4 \\
\cline { 2 - 7 } $\begin{array}{c}\text { Kampu } \\
\text { ng KB }\end{array}$ & $\begin{array}{c}\text { Seda } \\
\text { ng }\end{array}$ & $\sum$ & $50 \%$ & $50 \%$ & $0 \%$ & $100 \%$ \\
\cline { 2 - 7 } & $\begin{array}{c}\text { Ting } \\
\text { gi }\end{array}$ & $\sum$ & 0 & 49 & 1 & 50 \\
\cline { 3 - 7 } & & 0 & $0 \%$ & $23,9 \%$ & $76,1 \%$ & $100 \%$ \\
\hline \multicolumn{3}{|c|}{ Total } & 2 & 62 & 36 & 100 \\
\hline \multicolumn{3}{|c|}{$\%$} & $2,0 \%$ & $62,0 \%$ & $36,0 \%$ & $100,0 \%$ \\
\hline
\end{tabular}

Sumber : Data Primer, Tahun 2019

Berdasarkan perhitungan data pada Tabel 7 bahwa distribusi dari responden didapatkan efektifitas pembentukan kampung KB sedang hampir seluruh $(98 \%)$ perubahan perilaku masyarakatnya cukup.

Hasil penelitian ini secara analitik diuji statistik Spearman Rank (Rho) Test data yang diperoleh dari nilai sig.(2-tailed) sebesar 0,00 sehingga $\rho$ $<0,01 \quad(\alpha)$ diketahui bahwa ada hubungan efektifitas pembentukan kampung KB dengan perubahan perilaku masyarakat. Tingkat hubungan termasuk kategori sangat tinggi karena di dapatkan nilai Correlation Coefisien sebesar 0,778. Arah hubungan termasuk positif artinya semakin efektif pembentukan kampung KB maka perilaku masyarakat semakin baik.

Hal ini berarti bahwa semakin tinggi efektifitas pembentukan kampung KB maka perubahan perilaku masyarakat semakin baik.

\section{Pembahasan}

1. Kampung $\mathrm{KB}$ didesain sebagai upaya pembangunan keluarga sejahtera terhadap pengelolaan program KB. Kegiatannya dikelola berdasarkan prinsip dari, oleh dan untuk masyarakat. Tujuan akhirnya pembangunan masyarakat itu sendiri melalui perubahan perilaku masyarakat yang lebih baik ( Mardiyono, 2017). Apabila salah satu indikator progam kampung $\mathrm{KB}$ yaitu indikator proses belum sesuai target, maka perubahan perilaku masyarakat dengan adanya kampung KB belum mampu maksimal.

2. Hasil penelitian menunjukkan bahwa efektifitas pembentukan kampung KB setengah responden dalam kategori sedang, yaitu $(50 \%)$, responden dengan efektifitas pembentukan kampung $\mathrm{KB}$ rendah (4\%) dan responden dengan efektifitas pembentukan kampung $\mathrm{KB}$ 
tinggi $(46 \%)$. Perilaku responden sebagian kecil kurang (2\%), perilaku responden sebagian besar cukup (62\%) dan perilaku responden hampir setengahnya baik (36\%).

3. Hal ini belum sesuai dengan UndangUndang Republik Indonesia Nomor 52 Tahun (2009), yang merupakan hasil amandemen dari Undang-Undang Republik Indonesia Nomor 10 Tahun 1992 tentang Perkembangan Kependudukan dan Pembangunan Keluarga Sejahtera dalam Jurnal Cakrawala Vol. 11 No. 2 Desember 2007:129-136 oleh Mardiyono 2007 yaitu bahwa pembangunan harus ditujukan untuk meningkatkan kesadaran, kemauan dan kemampuan hidup keluarga/masyarakat yang setinggi-setingginya, sebagai investasi bagi pembangunan sumber daya manusia/masyarakat.

4. Efektifnya pembentukan kampung KB, tergantung dari perubahan perilaku masyarakat yang masih dalam kategori cukup. Hal ini berpengaruh terhadap program pembentukan kampung $\mathrm{KB}$ dikarenakan kesadaran masyarakat dalam berperilaku masih rendah (aminatuz Zuriyah, 2017). Posisi peran aktif masyarakat sangat penting artinya bagi kelancaran dan keberhasilan program kampung $\mathrm{KB}$ dan tercapainya tujuan secara mantap (Taat Wulandari, 2008).

5. Pada dasarnya pemerintah berkeinginan untuk membuat perubahan dari suatu kondisi tertentu ke keadaan lain yang lebih bernilai. Agar proses perubahan itu dapat menjangkau sasaran-sasaran perubahan keadaan yang lebih baik dan dapat digunakan sebagai pengendali masa depan (Taat Wulandari, 2008).

6. Hasil ini sejalan dengan Miftah Thoha,tth: 11-17 yang dikutip dari penelitian Taat wulandari, 2008 bahwa hambatan yang sering muncul ketika perilaku masyarakat terhadap suatu program pemerintah kurang maksimal bisa secara internal, berupa hambatan sosiokultural, dan hambatan dari birokrasi pemerintah. Hambatan internal, merupakan hambatan dari dalam masyarakat itu sendiri, yang merupakan keengganan sebagian besar warga masyarakatuntuk terlibat langsung dalam suatu program kegiatan. Hal ini disebabkan karena keadaan sosiokultural mereka yang belum memungkinkan untuk secara aktif menyuarakan keinginan mereka depan (Taat Wulandari, 2008).

7. Sementara mereka lebih memilih diam. Hambatan ini bukanlan merupakan hambatan yang fatal, sebab hamabatan ini masih bisa diperbaiki dengan cara memberikan masukan informasiinformasi baru yang positif dan bersifat membangun. Mereka harus dikenalkan dengan penemuan-penemuan dan perkembangan baru di daerah lain, yang nantinya akan membuka cakrawala berpikir mereka (Taat Wulandari, 2008).

8. Hubungan yang signifikan antara efektifitas pembentukan kampung KB dengan perubahan perilaku masyarakat mempunyai hubungan yang positif artinya keluarga yang bisadikatakan sejahtera, jika indikator proses Kampung $\mathrm{KB}$ berjalan sesuai harapan seperti yang ada dalam kegiatan kampung KB yaitu menjaga kebersihan lingkungannya, bisa menciptakan bahan makanan untuk dijual, menanam sayur agar bisa dikonsumsi sendiri ataupun dijual untuk meningkatkan ekonomi, merawat keturunan maksudnya untuk mendapatkan kasih sayang, pendidikan, makanan serta sandang yang layak dengan cara memberikan jarak kelahiran , mengajak para anak belajar mengaji, dan dapat mengajarkan para remaja yang belum bekerja untuk diajarkan tentang wiraswasta agar kedepannya bisa mempunyai pekerjaan dengan pembelajaran dari program-program Kampung KB.

9. Hal tersebut akan disesuaikan dengan Peraturan Pemerintah No 87 Tahun 2014 tentang Perkembangan Kependudukan 
dan Pembangunan Keluarga, Keluarga Berencana dan Sistem Informasi Keluarga. Dalam PP disebutkan delapan fungsi keluarga meliputi (1) fungsi keagamaan, (2) fungsi social budaya, (3) fungsi cinta kasih, (4) fungsi perlindungan, (5) fungsi reproduksi, (6) fungsi sosialisasi dan pendidikan, (7) fungsi ekonomi dan (8) fungsi pembinaan lingkungan (Artikel GPR. 2016).

\section{Simpulan}

Berdasarkan hasil analisis dan pembahasan didapatkan simpulan yaitu: efektifitas pembentukan kampung $\mathrm{KB}$ setengah responden dalam kategori sedang, yaitu (50\%), perilaku responden sebagian besar cukup (62\%). Terdapat nilai signifikansi sebesar 0,000 yang artinya terdapat hubungan signifikan antara efektifitas pembentukan kampung $\mathrm{KB}$ dengan perubahan perilaku masyarakat.

\section{Daftar Pustaka}

Aminatuz Zuhriyah. 2017. Kampung Keluarga Berencana dalam Peningkatan Efektivitas Program Keluarga Berencana. HIGEIA Uournal of Public Health Research and Development), Vol, No 4.

Arikunto, S. 2002. Prosedur Penelitian Suatu Pendekatan Praktek. Jakarta : Asdi Mahasatya.

Arikunto, Suharsimi. 2006. Prosedur Penelitian Suatu Pendekatan Praktik. Jakarta : Rineka Cipta.

Artikel GPR. 2016. Kampung KB Revolusi Program Keluarga Berencana Berbasis Masyarakat. Tersedia pada :

https://kominfo.go.id/index.php/conten t/detail/9841/kampung-kb-inovasistrategis-memberdayakanmasyarakat/0/artikel gpr [ 06 Juni 2016]

Arum Wahyuningsih. 2012. Kajian Karakteristik Kampung Keluarga Berencana (KB) di Desa Mojoranu Kecamatan Sooko Kabupaten
Mojokerto. Jurnal Mahasiswa Unesa.Vol 1, No1

Azwar, Saifuddin. 2007. Metode Penelitian. Pustaka pelajar: Yogyakarta.

Badan Kependudukan dan Keluarga Berencana Nasional. 2015. Petunjuk Teknis Kampung KB.

Badan Kependudukan dan Keluarga Berencana Nasional. 2017. Pedoman Pengelolaan Kampung KB. Jakarta : BKKBN.

Elisa Setiawati. 2017. Persepsi Masyarakat terhadap Program Kampung Keluarga Berencana di Kelurahan Pantoloan Boya Kecamatan Tawaeli. E-Journal GeoTadulako UNTAD. Vol 5, No 1

Mardiyono. 2017. Kampung KB sebagai Upaya Pemberdayaan Masyarakat/Keluarga di Jawa Timur. Jurnal Cakrawala. Vo.11 No 2, 129-136.

Notoatmodjo, S. 2012. Pendidikan dan Perilaku Kesehatan. Jakarta : Rineka Cipta.

Raikhani, A., Yunas Setia, N., Ratnasari, L., \& Hariastuti, I.2016. Analisa Kontribusi Program Kampung KB Dalam Upaya Pengingkatan Program KKBPK di Kab. Jombang, Provisinsi Jawa Timur. Jurnal Pengelolaan Sumberdaya Alam dan Lingkungan, Vol. 6,No. 1: 13-19. 
